\title{
An Empirical Study of Managing Knowledge Workers
}

\author{
K P Tripathi \\ Lecturer (MCA Programme) \\ Bharati Vidyapeeth Deemed University \\ Institute of Management, \\ Kolhapur, India
}

\begin{abstract}
We are living in a knowledge driven society fraught with uncertainty, market fluctuations, and aggressive competition. Today's emerging age of knowledge economy and knowledge management has created a new breed of company employees, whose intellectual capital is the accumulated experience, commitment and potential for developing and maintaining the learning organization. Such a breed is referred to as the knowledge worker. A knowledge worker puts people first. He or she leverages technology to maximize efficiency and corporate success round the clock. The driver of success in the new knowledge economy is knowledge. It is impressive that people can earn a living by working with something as intangible as knowledge. This paper is an attempt to highlights the study of managing knowledge workers.
\end{abstract}

\section{Keywords}

Knowledge Management, Knowledge workers, Explicit Knowledge, Tacit Knowledge, Knowledge Building Model, Work Adjust Model for Knowledge Workers.

\section{INTRODUCTION}

In this competitive world, companies can no longer build a competitive advantage through cost focus, as it is no longer a differentiator and most leading organizations have equalized on this account. In this knowledge based economy, if an organization wants to win, the knowledge of every employee must be converted into a pool that the entire organization can benefit from. But, what is knowledge? Information is readily captured in documents or in databases; even large amounts are fairly easy to retrieve with modern information technology systems. Before acting on information, however, we need to take one more step. Only when information is combined with experience and judgment does it becomes knowledge. ${ }^{[8]}$

Knowledge has to be conveniently sorted out and stacked for use for everybody to access ${ }^{[11]}$ At Dr. Reddy's Labs, the emphasis has shifted from training to encouraging and sharing learning, and has set up a learning centre, ANKUR, where cross functional teams pass on their experiences on specific projects to others. Similarly, Amtrex's PRODOSH (Proactive, Profession, Productive Data Base Management Synchronization and Harmony) collates all knowledge on customers and influencers, refines and stores knowledge for proactive decision making. Forbes Marshall employs a concept named TECHNOLOGY KEEPING, where 25 people track the knowledge generation throughout the world in 25 specific fields, store it, structure it, and make it available to the right individuals in the organization. ${ }^{[11]}$ Thus, the emphasis of organization is on Knowledge Management that is increasingly being considered as a source of competitive advantage. Knowledge
Management is a system for managing, gathering, refining, analyzing and disseminating knowledge in all of its forms within an organization. Knowledge is a fluid mix of fragmented experiences, values, contextual information, expert insight and grounded intuition that provides an environment and framework for evaluation and incorporating new experiences and information. Knowledge Management systems get the right information to the right people at the right time, provide them with the tools for analyzing that information, and give them the power to respond to the insight they glean from that information - all at lightening speed.

A knowledge worker is a person who transforms business and personal experience into knowledge through capturing, assessing, applying, sharing, and disseminating it within the organization to solve specific problems. Knowledge workers are actually those workers in an organization who are sensitive to change. They constantly respond to the changes in the environment by gathering information and then arranging their work accordingly. With the accelerated pace of change, we should not hesitate in accepting the reality that all knowledge workers have significant place in the organization.

Knowledge workers in today's workforce are individuals who are valued for their ability to interpret information within a specific subject area. They will often advance the overall understanding of that subject through focused analysis, design and/or development. They use research skills to define problems and to identify alternatives. Fueled by their expertise and insight, they work to solve those problems, in an effort to influence company decisions, priorities and strategies. Knowledge workers may be found across a variety of information technology roles, but also among professionals like teachers, lawyers, architects, physicians, nurses, engineers and scientists. As businesses increase their dependence on information technology, the number of fields in which knowledge workers must operate has expanded dramatically.

Generally, if the knowledge can be retained, knowledge worker contributions will serve to expand the knowledge assets of a company. While it can be difficult to measure, this increases the overall value of its intellectual capital. In cases where the knowledge assets have commercial or monetary value, companies may create patents around their assets, at which point the material becomes restricted intellectual property. In these knowledgeintensive situations, knowledge workers play a direct, vital role in increasing the financial value of a company.

The following interventions can act as tools for proper management of knowledge workers and for enhancing their performance: 
1. Job Design (team work)

2. Authority or Autonomy at work place

3. Loyalty towards the organization.

4. Training \& Development

5. Motivation (Competitive compensation/ reward packages and other incentives)

6. Communication Channels

7. Monitoring and Evaluation

8. Work Life Balance

\section{EXPLICIT AND TACIT KNOWLEDGE}

Knowledge Management is the process by which the organization generates wealth from its intellectual or knowledge based assets. Knowledge can be broadly classified as explicit knowledge and tacit knowledge ${ }^{[13]}$. Explicit knowledge is that which the individuals are able to express through various means of communication, and tacit knowledge is that which an individual is unable to articulate and express it. Another way to classify knowledge, which is more helpful for knowledge management is known knowledge, i.e. knowledge the individual knows and unknown knowledge i.e. knowledge the individual does not know because it has become embedded in the way the individual works.

Explicit knowledge is documented information that can facilitate action. It can be expressed in formal, shared language. Examples include formulas, equations, rules, and best practices.

\subsection{Explicit knowledge is:}

- Packaged

- Easily codified

- Communicable

- Transferable

Tacit knowledge is know-how and learning embedded within the minds of the people in an organization. It involves perceptions, insights, experiences, and craftsmanship.

\subsection{Tacit knowledge is:}

- Personal

- Context-specific

- Difficult to formalize

- Difficult to communicate

- More difficult to transfer

Most business actions require the guidance of both explicit and tacit knowledge. How does knowledge work in organizations? Knowledge originates in individuals, but it is embodied in teams and organizations. In an organization, examples of explicit knowledge are strategies, methodologies, processes, patents, products, and services. Examples of tacit knowledge in an organizational context are skills and competencies, experiences, relationships within and outside the organization, individual beliefs and values, and ideas. Knowledge also is embedded in work processes, and it exists in all core functions of an organization as well as in its systems and infrastructure. Effective knowledge management programs identify and leverage the know-how embedded in work, with a focus on how it will be applied. The challenge in knowledge management is to make the right knowledge available to the right people at the right time. ${ }^{[10]}$

\section{EMERGENCE OF A KNOWLEDGE WORKER}

According to Peter Drucker what we refer to as the information revolution is in fact a knowledge revolution. Software is the reorganization of traditional work, based on centuries of experience, through the application of knowledge and especially of systematic logical analysis. (Peter F. Drucker, Managing in the Next Society) Electronics is not the key here. Cognitive science is. This suggests that organizations which want to maintain leadership in the economy and the technology that are going to emerge in the future need to give enough consideration to the social position of the knowledge professionals and their values.

Traditionally, capital has been treated as the key resource, the financier as the boss, and knowledge workers as employees who would be content with bonuses and stock options. Drucker says that this attitude will work only as long as the stock markets are booming. The major industries are likely to grow more like traditional industries - slowly, painfully and laboriously - unlike Internet companies. These major industries are going to depend on knowledge workers. These workers won't be content with fringe benefits such as stock options and bonuses. Financial incentives won't prevent people from leaving.

Companies that implemented compensation systems that offered benefits and stock options have the highest turnover. In fact, ExMicrosoft people hate Microsoft ${ }^{[8]}$. They feel that the only thing that was offered to them at Microsoft was money. They resent lack of recognition at Microsoft. In other words, they could not adapt themselves to a value system that is entirely financial because they regarded themselves as professionals and applied scientists. In other words, their value system was different from Microsoft's value system.

Running an organization with "shareholder value" as its goal and justification can become counterproductive, because the performance of these knowledge -based organization will depend to a large extent on how they can attract, hold and motivate knowledge workers. Since these people can't be satisfied with money, they should be offered recognition and power within the organization. This is possible only when subordinates are treated as fellow executives and employees as partners.

\section{ROLE OF KNOWLEDGE WORKER}

It is through the means of formal education that a knowledge worker gains access to work, job and social position. A fairly limited amount of knowledge may be required in some kinds of knowledge work for e.g. some paramedical technicians such as XRay machine operator, a clinical laboratory technician or pulmonary technologists. On the contrary, far more advanced theoretical knowledge is required for some other kinds of knowledge work such Software development, Systems Analysis and design, Project Management, etc. Since knowledge workers works in teams and since knowledge work is more effective when it is more specialized, the team, rather than the individual becomes the actual work unit. Further, the effectiveness of a knowledge worker will depend upon the manager's ability to diagnose what kind of team is required to execute effectively a certain kind of knowledge work, and the ability to organize such a team and to integrate the worker into it.

Knowledge, unlike any of the traditional key resources like land, labor and capital, is not tied to any country but is transnational, portable and can be created everywhere, fast and cheap. Knowledge is forever changing and makes itself obsolete within a short period of time. The only thing that can be predicted about a competitive advantage of a country, an industry, an institution, or an individual, 
based on knowledge, is that the advantage will soon be challenged, possibly by a total newcomer. ${ }^{[7]}$

Acquisition of knowledge, or learning, therefore, can no longer stop at any age. Life-long learning or continuous learning during one's working life will increasingly be a requirement for all knowledge workers. Also, while it is possible to define what productivity is with respect to the manual worker, it is not so in the case of a knowledge worker. The measurements of productivity for a manual worker such as number of pieces turned out per hour or per dollar wage prove to be irrelevant if applied to the knowledge worker. Productivity in case of a knowledge worker is primarily in terms of quality.

\section{KNOWLEDGE MANAGEMENT KNOWLEDGE-BASED ENTERPRISES}

IN

In this knowledge-based economy, every organization is trying to focus on knowledge as a source of competitive advantage. Organizations should pursue the Knowledge management initiative by analyzing their own strengths, capabilities and needs and evolve an appropriate Knowledge management model, suitable for their organization. The knowledge management initiative can be attempted at a smaller level through a pilot project and then it can be extended to the organization as a whole. Firms that want to compete with core knowledge and acquire additional innovative knowledge should pursue Knowledge Management. ${ }^{[4]}$

Figure 1: A Work Adjustment Model for Knowledge Workers

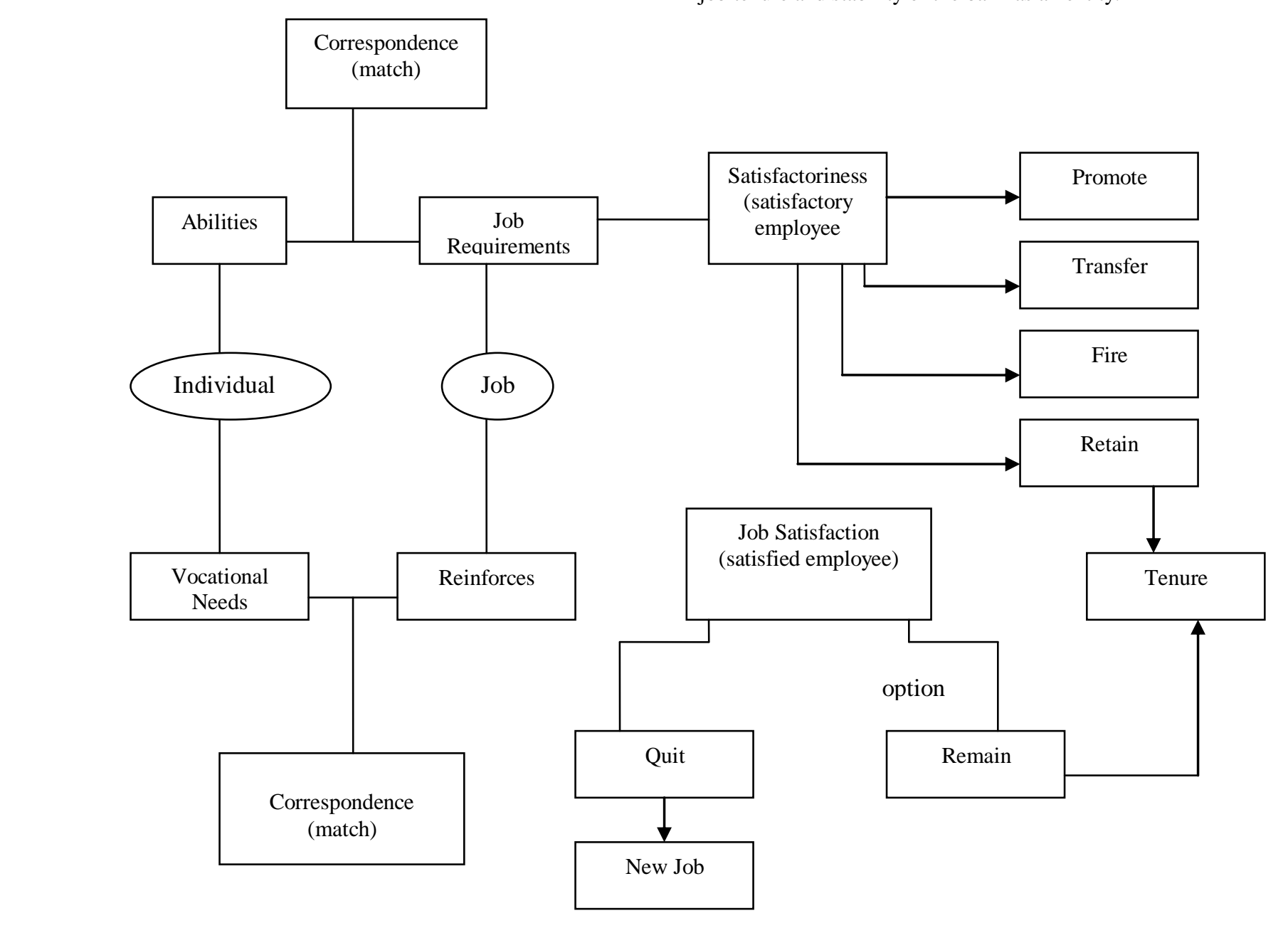

\section{WORK ADJUSTMENT AND THE} KNOWLEDGE WORKER

Smart managers strive to ensure the right match between the vocational needs of their knowledge workers and the requirements of their jobs. The goal is to assure stability of the workforce and continuity on the job in the interest of the corporation. On approach to work adjustment is a model developed by a group of counseling psychologists at the University of Minnesota who were concerned with the general problem of adjustment to work (Dawis, Lofquist, and Weiss 1968). The model is based on the concept of "correspondence" or a match between the individual and his or her work environment. ${ }^{[4]}$

Achieving and maintaining correspondence with the work environment are viewed as basic motives of human work behavior. As shown in Figure 1, correspondence begins when the individual brings certain skills (abilities) that enable him or her to "respond" to the requirements of the job or the work environment. On the other hand, the work environment provides certain rewards (reinforcers such as wages, prestige, personal relationships, and so on) in response to the individual's requirements. When both the individual's and the work environment's minimal requirements are mutually fulfilled, correspondence exist. When the individual achieves minimal correspondence, he or she is allowed to stay on the job and have an opportunity to work toward a more optimal correspondence and to stabilize the correspondence relationship. When this relationship (correspondence) continues, it contributes to job tenure and stability of the bank as an entity. ${ }^{[4]}$ 


\section{KNOWLEDGE BUILDING MODEL}

Knowledge Management tools can be used to support the automation or augmentation of organizational knowledge management. Below are listed the various KM Models: ${ }^{[2]}$

1. Orientation Model: To provide information that will help employees to understand the context and content of their work so they may perform readily and effectively.

2. Mentorship Model: Mentorship programmes are intended to provide a mechanism for the transfer of knowledge from one generation of employees to the next to preserve institutional memory and to help offer professional development opportunities for both 'mentees' and 'mentors'. For mentees, the effective mentorship programme is intended to reduce individual isolation, enhance career development, improve employee satisfaction, aid in the improvement of technical skills, and helps to define career paths. In the case of mentors, the programme is structured to help build successful teams, identify high potential individuals, improve communication with different levels of the organization, and encourage new and innovative approaches to problem solving.

3. Internship Model: Internships and fellowships offer training and experiential learning opportunities. Provided by organizational leaders, volunteer managers or supervisors, and professional trainers, internships and fellowships are typically awarded to high achieving individuals for a 6-month to 1-year period.
4. Job Rotation Model: To effectively transfer corporate knowledge from one generation to another and to develop existing staff in a way that allows them to move upward in the organization. Job rotation participants move through a variety of departments and are given assignments and training similar to that given to a new full-time employee. Some programs hold the participant's career position for them during training; others require the participant to resign from their position to participate. In the later case, the expectation is that the participant will apply and be accepted for a higher-level position when the training is complete.

5. After Action Review Model: To capture both explicit and tacit knowledge and provide a greater context for that knowledge. An after-action review is a professional discussion of an event, focused on performance standards, enabling team members to discover what happened, why it happened, and how to sustain strengths and improve weakness in performance.

6. Communities of Practice Model: Communities of Practice are groups of people who come together to share and learn from one another face-to-face and virtually. They are held together by a common interest in a body of knowledge and are driven by adesire and need to share problems, experiences, insights, templates, tools and best practices.

7. Phased Retirement Model: To enable employers to retain the services of highly skilled, highly motivated employees who are at or nearing retirement.

Figure 2: Knowledge Building Model

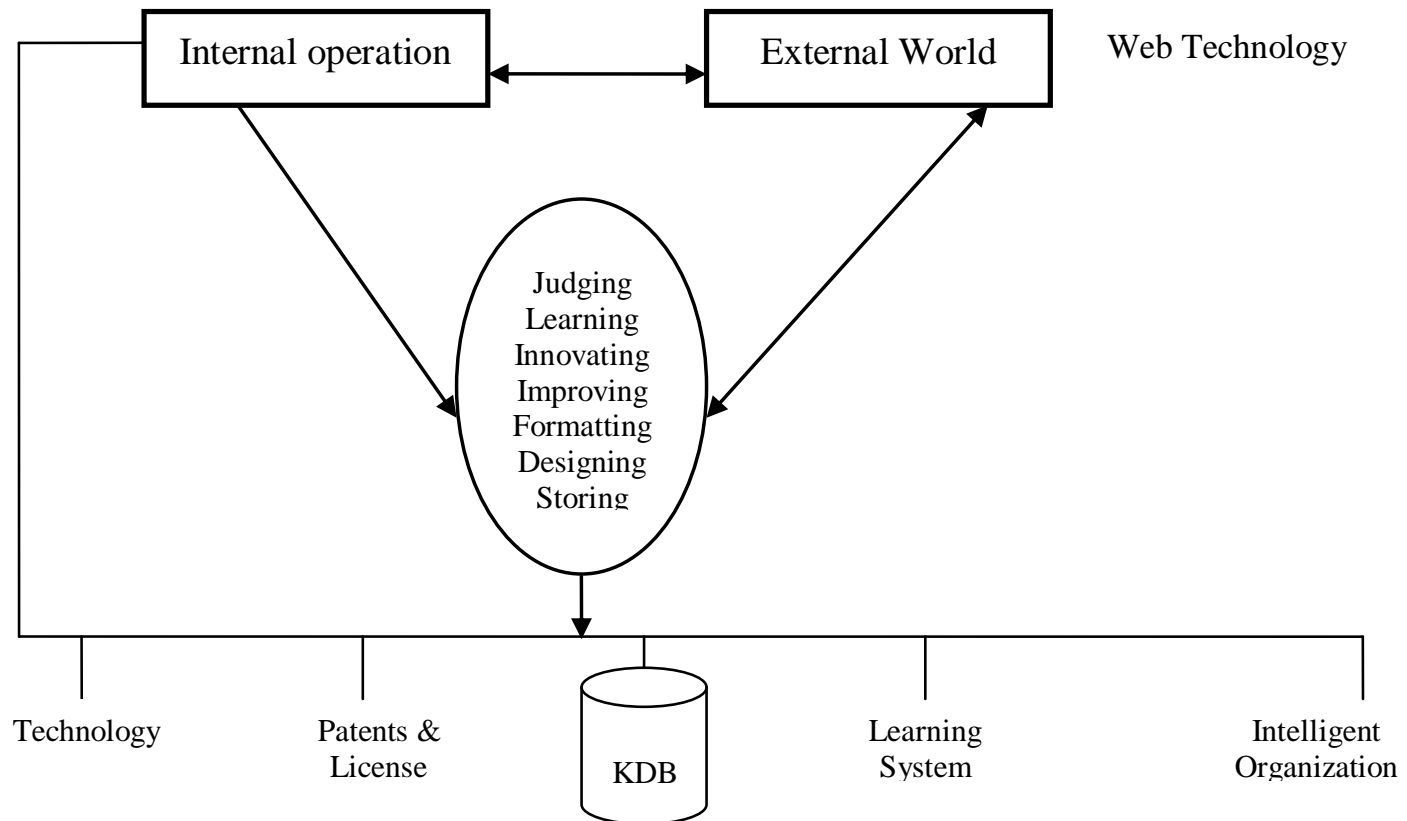




\section{KNOWLEDGE MANAGEMENT ARCHITECTURE}

The four basic knowledge processes are development, distribution of knowledge, knowledge consolidation and combination of knowledge. The analysis, plan and action are usually formulated in terms of the four basic operations on knowledge that can be found in the organization [7]. The organization structure can significantly affect the pace of knowledge sharing.

\section{Figure 3: Knowledge Management Architecture}

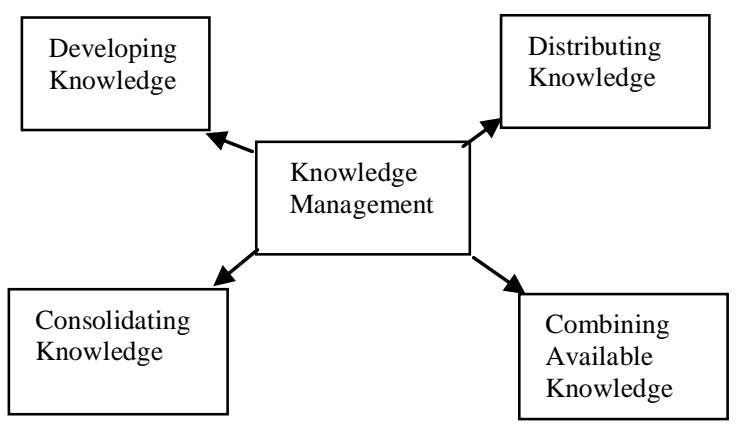

1. Developing Knowledge: In today's global competition, it is necessary to develop new knowledge based on creative ideas, analysis of failure, daily experience and work in Research and Development department. Corporate memories can support these processes by recording failures and successes. It is necessary to give more explicit recognition to tacit knowledge and related human aspects, such as ideas, values, or emotions, for developing a richer conceptualization of knowledge management

2. Consolidating Knowledge: Knowledge must be safeguarded against loss due to different causes such as retirement, transfer, death etc. Consolidation of knowledge is supported by corporate memories and knowledge transfer programs. The knowledge thus stored must be available at the right time and at right place.

3. Distributing Knowledge: Knowledge must be actively distributed to those who can make use of it. The turnaround speed of knowledge is crucial for the competitiveness of companies. To distribute the knowledge implement new, flexible technologies and systems that support and enable communities of practice, informal and semi-informal networks of internal employees and external individuals based on shared concerns and interests.

4. Combining Available Knowledge: An organization can only perform at its best, if all available knowledge areas are combined in its new products.

A good knowledge management system should involve the continuous streamlining of the above four basic knowledge processes to improve the organizational learning capability. The value of knowledge management relates directly to the effectiveness with which the managed knowledge enables the members of the organization to deal with today's situations and effectively envision and create their future ${ }^{[2][11]}$

\section{TECHNOLOGY AND THE KNOWLEDGE WORKER}

Knowledge work focuses on thinking, using information for processing, and recommending value-added change. The primary activities of knowledge work are assessment, decision making, monitoring and scheduling. A knowledge worker is a manager, a supervisor, or a clerk who is actively involved in thinking, processing information, analyzing, creating, or recommending procedures based on experience and cumulative knowledge. For example, a stockroom clerk's job may be highly structured; therefore, it provides limited knowledge work. In contrast, a head teller job in a bank entails a significant amount of knowledge work, including the following:

1. Assessing the amount of cash available in the teller's drawer before the lunch break.

2. Deciding on the procedure to use in handling irate customers.

3. Monitoring cash supply for the drive-in tellers on Friday, when employees of a local plant cash their paychecks.

4. Scheduling lunch breaks of available tellers during the flu season.

Most people have an innate ability for problem-solving. However, routine activities often make it difficult to concentrate on the creative phase of problem-solving. This situation can be improved in an IT environment that provides the following:

1. A Knowledge-based retrieval system that generates knowledge and ideas quickly.

2. Interactive functions to derive feasible solutions.

3. Functions to communicate a knowledge worker's activities to the appropriate people at the appropriate time via technology such as e-mail or an internet.

IT plays a role in the learning organization in three key processes: knowledge capture, information distribution, and information interpretation. In knowledge capture, a place for It is in market research and competitive intelligence systems. Likewise, the use of e-mails, intranets, and bulletin boards can facilitate information distribution and interpretation.

\section{MOTIVATING KNOWLEDGE WORKERS}

Few companies can say that their employees are not their most valuable assets; Knowledge management can help every company take better care of its employees. With an effective knowledge management solution, companies can better motivate their employees, better reward them and align their skills with corporate needs.

Effective knowledge-management solutions deliver training, track employees' skills and competencies, remove barriers to productivity, provide current company information, manage benefits, help supervisors staff their departments, and simplify expense reimbursement. Dynamic market conditions can catch companies without valuable skills sets across its employees. For e.g. Knowledge-management systems can identify skills gaps as well as provide mechanisms for closing those gaps.

Knowledge management can help companies save significant sums of money by enabling them to improve employee management. Key areas, in which knowledge management is most effective, include the following ${ }^{[8]}$ :

1. Training helps keep knowledge workers employees sharp: It can take many forms, including multimedia, online handbooks and manuals, and so on. 
2. Skill alignment ensures that the right people are working on the right projects at the right time: Knowledge management enables companies to find experts that are available for a particular job.

3. Benefits management is a natural target for any knowledge management system: Companies can simplify paper-based systems, reduce HR costs, provide corporate information to employees, and more.

4. Bigger companies can benefit most from better staffing management: Using knowledge management, those companies can keep track of headcount and reorganize more quickly.

5. Performance reviews, are more efficient when moved from manual processes to knowledge-management system: As a result, reviews are completed on time, and supervisors can better manage their budgeting processes.

6. Expense reimbursement is best done on an internet: Companies can significantly reduce the cost and turnaround time for reimbursing employees for out-of -pocket expenses, improving morale and productivity.

\section{CONCLUSION}

We are moving into an age where business is measured not in terms of historical performance, but in terms of how it makes use of the knowledge and intellectual capital of its knowledge workers. New human management challenges arise from the increasing demand for knowledge workers. This means encouraging productive knowledge to come forward and encouraging employees to learn. In managing knowledge workers, a manager must keep in mind time constraints, working smarter and harder but achieving little, knowledge workers doing the wrong job, work schedule and deadlines, and motivational forces against knowledge work productivity. Thus, the driver of success in the new economy is knowledge. Knowledge embodies experience, innovation and creativity.

\section{REFERENCES}

[1] A Thothathri Raman, Knowledge Management, Excel Publication, New Delhi.

[2] Arpita Gopal, Chandrani Singh, e-World : Emerging Trends in Information Technology, Excel Publication, New Delhi (2009).

[3] C.T.Bhunia, Introduction to Knowledge Management (Everest Publishing House, 2006).
[4] Elias M. Awad, Hassan M. Ghaziri, Knowledge Management, Pearson Education Pvt. Ltd. New Delhi (2008).

[5] Gerald Bernbom, Information Alchemy: The Art and Science of Knowledge Management

[6] Irma Becerra-Fernandez, Avelino Gonzalez, Rajiv Sabherwal, Knowledge Management-Challenges Solutions and Technologies, Pearson Education Pvt. Ltd. New Delhi (2009).

[7] Jerry Honeycutt "Knowledge Management Strategies"

[8] Peter F. Drucker "Management challenges for the $21^{\text {st }}$ century" First published 1999, Eight reprint 2003, Replika Press Pvt. Ltd. Kundli 131028.

[9] Peter F. Drucker, Managing in the Next Society

[10] Ratnaja Gogula "Knowledge Management - A new dawn" ICFAI University Press

[11] Reddy B. R., Knowledge Management-Tools for Business Development, Himalaya Publishing House, Mumbai.

[12] Stuart B., Knowledge Management-Theory and Practice, Thomson Learning, New Delhi.

[13] Tapas Mahapatra and Shalini Khandelwal, "Knowledge Management - Design and implementation"

[14] Thomas, J.C., Kellogg, W.A. \& Erickson, T, The knowledge management puzzle: human and social factors in knowledge management, IBM Systems Journal, 40(4), 863-884, 2006.

[15] Warier S, Knowledge Management, Vikas Publishing House, New Delhi.

\section{AUTHORS BIOGRAPHY}

K P Tripathi received his M.C.A., degree from Shivaji University, Kolhapur in June 2006 and M.B.A. degree from YCMOU, Nashik in Feb. 2010. He is working as Lecturer in M.C.A. Department, Bharati Vidyapeeth Deemed University Institute of Management, Kolhapur, India. He has presented 5 papers in National Conference and 4 papers in International Conference and 3 in International Journals. His areas of interest include Information Technology, Computer Organization \& Architecture, and Mobile Communication. 